\title{
Dual-functionalized large pore mesoporous silica as an efficient catalyst for bisphenol-A synthesis
}

\author{
Chin-Chang Chen ${ }^{a, 1}$, Soofin Cheng ${ }^{a, *}$, Ling-Yun Jang ${ }^{b}$ \\ a Department of Chemistry, National Taiwan University, No. 1, Roosevelt Road, Sec. 4, Taipei 10674, Taiwan \\ ${ }^{\mathrm{b}}$ Research Division, National Synchrotron Radiation Research Center, Hsinchu 300, Taiwan
}

Received 20 January 2007; received in revised form 5 April 2007; accepted 30 April 2007

Available online 10 May 2007

\begin{abstract}
Mesoporous SBA-15 materials dual-functionalized with arenesulfonic acid and mercapto (or disulfide) groups were synthesized by cocondensation of tetraethylorthosilicate (TEOS) and organosilane precursors in the presence of $\mathrm{EO}_{20} \mathrm{PO}_{70} \mathrm{EO}_{20}(\mathrm{P} 123)$ copolymer under acidic condition. The amount of sulfur incorporated in the silica framework increased with the concentrations of the organosilane precursors in the synthesis gel, and sulfur contents up to $3.6 \mathrm{mmol} / \mathrm{g}$ silica could be obtained. Based on the sulfur K-edge X-ray absorption spectra, the chlorosulfonyl moieties in 2-(4-chlorosulfonyl-phenyl)ethyltriethoxysilane (CSPETES) precursors were completely in situ hydrolyzed to sulfonic acid, while a large portion of the mercapto groups was oxidized to disulfide under the synthesis condition. The dual-functionalized SBA-15 was much more efficient as catalysts than the single functionalized counterparts in condensation of phenol and acetone to form bisphenol-A. Both mercapto and disulfide groups demonstrated promoter effect in formation of $p$, $p^{\prime}$-bisphenolA. Moreover, ordered mesopores facilitated the diffusion of reactants and the accessibility of the catalytic and promoting sites.

(C) 2007 Elsevier Inc. All rights reserved.
\end{abstract}

Keywords: Dual-functionalized; Mesoporous silica; Bisphenol-A; Arenesulfonic acid; Thiol; Disulfide

\section{Introduction}

2,2-Bis(4-hydroxyphenyl)propane, more commonly known as bisphenol-A, is a valuable raw material used in the production of many polymers and is a fundamental building block of epoxy resins and polycarbonates. The end-products are used in a range of applications; including adhesives, potting compounds, clear protective cases, headlight covers, and lenses. In the past few years, a rapidly growing demand for bisphenol-A in industrial scale is for use in high-tech production, such as compact discs and digital video discs. The compound is customarily manufac-

\footnotetext{
${ }^{*}$ Corresponding author. Fax: +886223638017.

E-mail address: chem1031@ntu.edu.tw (S. Cheng).

${ }^{1}$ Large portions of the results are abstracted from a thesis submitted by C.-C. Chen to the Faculty of National Taiwan University in partial fulfillment of the requirement for the degree of Master of Science in 2004.
}

tured by an acid-catalyzed condensation reaction of acetone and phenol as shown in Scheme 1. In industry, ion-exchange resins are used worldwide to produce bisphenol-A in bulk quantities. The use of mineral acid catalysts is avoided for their corrosive nature. It has been reported in patent literature that thiol-modified ion-exchange resins, Amberlyst, exhibited very good catalytic activity for bisphenol-A synthesis with about $90 \%$ selectivity to the desired $p, p^{\prime}$-bisphenol-A $[1,2]$. Nevertheless, the thermal stability of resin catalysts limit them from operation at higher reaction temperatures and fouling of the resin catalysts in the reaction medium can also be a problem. As a result, still many attempts have been made to develop thermally stable solid catalysts for bisphenol-A synthesis.

Strong solid acids are considered an environmentally friendly alternative for the hazardous and corrosive mineral acid catalysts such as $\mathrm{H}_{2} \mathrm{SO}_{4}, \mathrm{HF}$ and $\mathrm{ClSO}_{3} \mathrm{H}$ commonly used in many industrial processes [3-6]. Acidic 


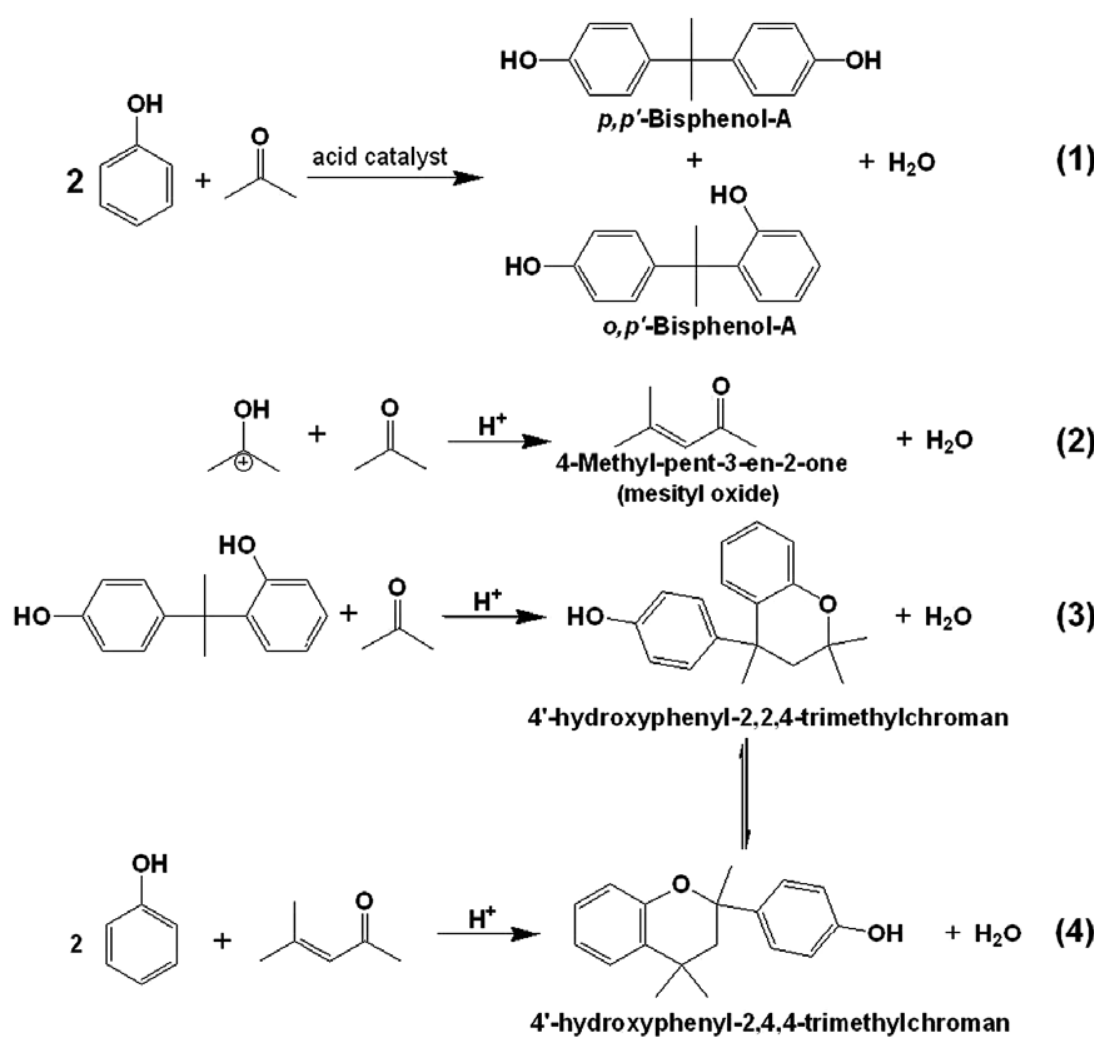

Scheme 1. Reactions in the condensation of phenol and acetone.

ion-exchange polymer resins such as Nafion resin with a high acid strength have been shown to be an effective catalyst for a wide range of acid-catalyzed reactions [7-9]. However, the surface area of the resin is very low $\left(0.02 \mathrm{~m}^{2} \mathrm{~g}^{-1}\right.$ or less) and most of the active sites are buried within the polymer matrix. As a result, the sites are inaccessible or poorly accessible under many reaction conditions and low catalytic activities were observed. As an alternative, the ordered mesoporous silica materials covalentfunctionalized with aliphatic or aromatic sulfonic acid groups by post-synthesis or co-condensation have been reported and successfully used in several acid-catalyzed reactions [10-21]. The catalytic activities of solid acid catalysts are also dramatically influenced by the acid strength $[17,18,22]$. Compared with aliphatic sulfonic acid groups, aromatic sulfonic acid groups with a phenyl group adhered to the sulfonic group usually show higher acid strength and greater catalytic activities in acid-catalyzed reactions, such as in the Fries rearrangement of phenyl acetate and Beckmann rearrangement of cyclohexanone oxime [17,18].

Ordered mesoporous silica anchored with propylsulfonic acid groups by post-synthesis was reported to be very effective in the synthesis of $p, p^{\prime}$-bisphenol-A with very high selectivity at relatively low reaction temperature [23-25]. Recently, Zeidan et al. [26] studied both homogeneous and SBA-15-immobilized sulfonic acid catalysts and reported that thiol groups in proximity were likely to have cooperative effect in accelerating the rate of bisphenol-A synthesis and shifting the regioselectivity to favor $p, p^{\prime}-$ bisphenol-A formation. In the present paper, a series of arenesulfonic acid and thiol dual-functionalized mesoporous SBA-15 materials were prepared by one-pot co-condensation [27]. The catalytic performance of resultant materials in bisphenol-A synthesis was examined, and the focus was on the chemical nature of the mercapto function groups and the effect of dual functionalities. Because a large portion of the mercapto groups was oxidized to disulfide in the synthesis process, the role of disulfide in promoting the catalytic activity was also studied. In addition, the effect of silica materials with different mesoporous structures in the catalytic reaction was also compared.

\section{Experimental}

\subsection{Materials}

Surfactant $\mathrm{P} 123\left(\mathrm{EO}_{20} \mathrm{PO}_{70} \mathrm{EO}_{20}, M_{\mathrm{av}} \sim 5800\right)$, tetraethylorthosilicate (TEOS, 98\%), 2-(4-chlorosulfonylphenyl)ethyltriethoxysilane (CSPETES, 50\% solution in dichloromethane) and bisphenol-A were purchased from Aldrich. (3-Mercaptopropyl)trimethoxysilane (MPTMS, 97\%) and 3-cyanopropyltriethoxysilane (CPTES, 96\%) were purchased from Fluka. Triblock copolymer Pluronic F127 $\left(\mathrm{EO}_{106} \mathrm{PO}_{70} \mathrm{EO}_{106}, M_{\mathrm{av}} \sim 12,600\right)$ was from BASF. Other chemicals were from Acros. All chemicals were used as received. 


\subsection{Syntheses}

\subsubsection{Arenesulfonic acid and thiol dual-functionalized \\ SBA-15 series}

Arenesulfonic acid and thiol dual-functionalized SBA15 materials were prepared through co-condensation method. In the typical synthesis, $4.0 \mathrm{~g}$ of Pluronic P123 was dissolved in $160 \mathrm{~mL}$ of $2 \mathrm{M} \mathrm{HCl}$ solution and the mixture was stirred at $40{ }^{\circ} \mathrm{C}$ for $1 \mathrm{~h}$. After adding TEOS, the resultant solution was hydrolyzed at $40{ }^{\circ} \mathrm{C}$ for $3 \mathrm{~h}$ prior to the addition of 3-mercapto-propyltrimethoxysilane (MPTMS) and the arenesulfonic acid precursor 2-(4-chlorosulfonyl-phenyl)ethyltriethoxysilane (CSPETES). The resulting mixture was stirred for another day at $40{ }^{\circ} \mathrm{C}$, followed by transferring to a polypropylene bottle and reacting at $90{ }^{\circ} \mathrm{C}$ for $24 \mathrm{~h}$ under static condition. The molar composition of the mixture was $(0.9-x)$ TEOS: 0.1 CSPETES: $x$ MPTMS: $7.6 \mathrm{HCl}$ : 0.017 P123: $185 \mathrm{H}_{2} \mathrm{O}$, where $x$ ranged from 0.02 to 0.15 . The solid product was collected by filtration and dried in an oven at $50{ }^{\circ} \mathrm{C}$ overnight. The template was removed from the as-synthesized

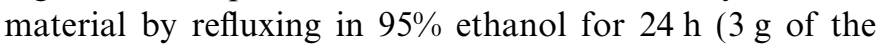
as-synthesized product per $800 \mathrm{~mL}$ of ethanol). Subsequently, the extracted product was filtered off, washed with ethanol and was finally dried at $100{ }^{\circ} \mathrm{C}$ overnight. The samples were abbreviated as $\mathrm{S} 15-\mathrm{Ar}-\mathrm{SO}_{3} \mathrm{H}(X \%)-\mathrm{SH}(Y \%)$. The numbers $X$ and $Y$ in parentheses indicate the percentage of silicon atoms from the initial mixture of CSPETES and MPTMS.

\subsubsection{Thiol-functionized $S B A-15$ and its oxidized derivative}

SBA-15 functionalized with $20 \%$ mercaptopropyl groups was prepared following similar synthesis steps given above except CSPETES was not added. The molar composition of the synthesis mixture was 0.8 TEOS: 0.2 MPTMS: 7.6 $\mathrm{HCl}$ : $0.017 \mathrm{P} 123$ : $185 \mathrm{H}_{2} \mathrm{O}$. The sample was abbreviated as $\mathrm{S} 15-\mathrm{SH}(20 \%)$.

The mercaptopropyl functional groups were oxidized to form propyl sulfonic acid by heating $0.3 \mathrm{~g}$ of $\mathrm{S} 15-\mathrm{SH}(20 \%)$ with $10 \mathrm{~mL}$ of $35 \mathrm{wt} \% \mathrm{H}_{2} \mathrm{O}_{2}$ for $3 \mathrm{~h}$, followed by filtration and washing the solid with $1.2 \mathrm{M} \mathrm{H}_{2} \mathrm{SO}_{4}$ and then with abundant water. The final product after dried at $100^{\circ} \mathrm{C}$ overnight was abbreviated as $\mathrm{S} 15-\mathrm{SH}(20 \%) \_\mathrm{O} 3 \mathrm{~h}$.

\subsubsection{Arenesulfonic acid and disulfide dual-functionalized $S B A-15$}

The disulfide silane $\left[\left(\mathrm{CH}_{3} \mathrm{O}\right)_{3} \mathrm{Si}-\left(\mathrm{CH}_{2}\right)_{3}-\mathrm{S}-\right]_{2}$ was synthesized via the reaction of (3-mercaptopropyl)trimethoxysilane (MPTMS) and 2,2'-dithiodipyridine according to the literature [28]. An excess of MPTMS (4.45 g, $22.6 \mathrm{mmol}$ ) was added rapidly via syringe to the $2,2^{\prime}$-dithiodipyridine $(2 \mathrm{~g}, 9.07 \mathrm{mmol})$ in $\mathrm{CH}_{2} \mathrm{Cl}_{2}(20 \mathrm{~mL})$ solution, and the yellow solution was stirred at room temperature for 4 days. The resultant disulfide silane was then purified by extraction with petroleum ether.

Mixed arenesulfonic acid and disulfide-functionalized SBA-15 was synthesized via co-condensation of TEOS with disulfide silane $\left[\left(\mathrm{CH}_{3} \mathrm{O}\right)_{3} \mathrm{Si}-\left(\mathrm{CH}_{2}\right)_{3}-\mathrm{S}-\right]_{2}$ following similar synthesis steps as those for arenesulfonic acid and thiol dual-functionalized SBA-15. The molar composition of the synthesis mixture was 0.8 TEOS: 0.1 CSPETES: $0.5\left[\left(\mathrm{CH}_{3} \mathrm{O}\right)_{3} \mathrm{Si}-\left(\mathrm{CH}_{2}\right)_{3}-\mathrm{S}-\right]_{2}: \quad 7.6 \mathrm{HCl}: 0.017 \quad \mathrm{P} 123: 185$ $\mathrm{H}_{2} \mathrm{O}$. The sample was abbreviated as S15-Ar$\mathrm{SO}_{3} \mathrm{H}(10 \%)-\mathrm{S}-\mathrm{S}(10 \%)$.

\subsubsection{Arenesulfonic acid and thiol dual-functionalized SBA-16 and amorphous silica}

Mixed arenesulfonic acid and thiol-functionized SBA-16 was synthesized using triblock copolymer $\mathrm{EO}_{106} \mathrm{PO}_{70} \mathrm{EO}_{106}$ (Pluronic F127) as template. The synthesis procedure was similar to that for dual-functionalized SBA-15 as described above. The molar composition of the mixture was 0.75 TEOS: 0.1 CSPETES: 0.15 MPTMS: $7.6 \mathrm{HCl}$ : 0.017 F127: $185 \mathrm{H}_{2} \mathrm{O}$. The final product was abbreviated as $\mathrm{S} 16-\mathrm{Ar}-\mathrm{SO}_{3} \mathrm{H}(10 \%)-\mathrm{SH}(15 \%)$.

Amorphous silica dual-functionalized with arenesulfonic acid and mercapto groups was prepared by co-condensation of TEOS, CSPETES and MPTMS under acid condition without the addition of pore-directing templates. TEOS was first hydrolyzed in $160 \mathrm{~mL}$ of $2 \mathrm{M} \mathrm{HCl}$ solution for $20 \mathrm{~h}$ at $40^{\circ} \mathrm{C}$. Then, the appropriate amount of CSPETES and MPTMS was slowly added into the transparent slightly viscous solution and the mixture was kept stirring at this temperature until the water was dried out. The molar composition of the mixture was 0.75 TEOS: 0.1 CSPETES: 0.15 MPTMS: $7.6 \mathrm{HCl}$ : $185 \mathrm{H}_{2} \mathrm{O}$. The obtained dry solid was washed with abundant water. Finally, the material in powder form was filtered, washed several times with ethanol and dried at $200{ }^{\circ} \mathrm{C}$. The final product was abbreviated as $\mathrm{SiO}_{2}-\mathrm{Ar}-\mathrm{SO}_{3} \mathrm{H}(10 \%)$ $\mathrm{SH}(15 \%)$.

\subsubsection{Characterization methods}

Powder X-ray diffraction (XRD) patterns were obtained using a Panalytical X'Pert Pro diffractometer with $\mathrm{Cu} \mathrm{K \alpha}$ radiation $(\lambda=1.5418 \AA)$ operated at $45 \mathrm{kV}$ and $40 \mathrm{~mA}$. Nitrogen adsorption-desorption isotherms were measured at $-196{ }^{\circ} \mathrm{C}$ on a Micromeritics Tristar 3000 analyzer. Samples were degassed at $200^{\circ} \mathrm{C}$ for $24 \mathrm{~h}$ before the measurements were taken. The specific surface areas were evaluated using Brunauer-Emmett-Teller (BET) method in the $p / p_{0}$ range of $0.05-0.3$. Pore size distribution was calculated using the Barrett-Joyner-Halenda (BJH) method based on the desorption branch of the isotherms, and the pore size was reported from the peak position of the distribution curve. The pore volume was taken at the $P /$ $P_{0}=0.990$ point.

Thermogravimetric analyses (TGA) were performed on a Du Pont 951 thermogravimetric analyzer. The samples were heated in air at a rate of $10^{\circ} \mathrm{C} / \mathrm{min}$ with air flow of $50 \mathrm{~mL} / \mathrm{min}$. Sulfur content in the solid product was analyzed using a Heraeus CHNS elemental analyzer.

Acid capacities of the sulfonic acid functionalized materials were determined by exchanging the protons in the 
solid with $2 \mathrm{M}$ sodium chloride solution [17,29]. After equilibration, the solid was filtered and the displaced protons in the solution were measured by potentiometric titration using $0.01 \mathrm{M}$ sodium hydroxide solution.

Sulfur K-edge X-ray Absorption Near Edge Spectra (XANES) were obtained at the beam line 15B at National Synchrotron Radiation Research Center in Hsinchu, Taiwan. Standard operating conditions were $1.5 \mathrm{GeV}$ and 120-200 mA. Photon energies were calibrated using the L-edge of pure Mo foil.

\subsubsection{Catalytic studies}

Condensation of phenol and acetone to form bisphenolA was carried out in liquid phase under atmospheric pressure in a $50 \mathrm{~mL}$ glass reactor equipped with a condenser and a magnetic stirrer. The reaction took place with acetone $(0.58 \mathrm{~g}, 0.01 \mathrm{~mol})$ and excess phenol (in most of the cases, $4.70 \mathrm{~g}, 0.05 \mathrm{~mol}$ ) in the presence of arenesulfonic acid functionalized silica materials $(0.10 \mathrm{~g})$. No other solvent was needed. The mixture was kept at $85^{\circ} \mathrm{C}$ for $24 \mathrm{~h}$. The final suspension was separated with a filtering syringe, and the resulting solution was analyzed by a Chrompak 9000 Gas Chromatography with a flame ionization detector and $30 \mathrm{~m} \times 0.53 \mathrm{~mm}$ RTX-50 capillary column. $O$-Xylene was used as an external standard. Individual reaction product was identified by GC-Mass spectrometry (HP6890 mass spectrometer connected with a $30 \times 0.25 \mathrm{~mm}$ RTX-50 capillary column).

\section{Results and discussion}

\subsection{Characterization of mesoporous materials}

Small-angle X-ray diffraction patterns of ethanol extracted arenesulfonic acid and thiol dual-functionalized SBA-15 materials are shown in Fig. 1. One intense peak indexed to (100) diffraction and higher order weak (110) and (200) diffractions appear for the sample functionalized with $10 \%$ arenesulfonic acid, suggesting a highly ordered, hexagonally arranged pore structure, characteristic of SBA-15 [30]. As mercapto groups were also introduced and the amount was increased, the peak width of the (100) diffraction becomes broader and the (110) and (200) diffractions become less resolved. This phenomenon is explained by considering that the presence of CSPETES and MPTMS organic silanes would perturb the self-assembly of the surfactant micelles and the silica precursors [17].

The $\mathrm{N}_{2}$ adsorption-desorption isotherms of modified SBA-15 with different amounts of CSPETES and MPTMS exhibit characteristic type IV isotherms (Fig. 2a). For the sample merely functionalized with $10 \%$ arenesulfonic acid, a steep increase in adsorption volume was seen around $p / p_{0}=0.7$, indicating that the material possesses similar large mesopores and narrow pore-size distribution as that of pure SBA-15. As mercapto groups were also introduced, the hysteresis loop becomes distorted and the desorption branches of the isotherms are twisted toward lower $p / p_{0}$

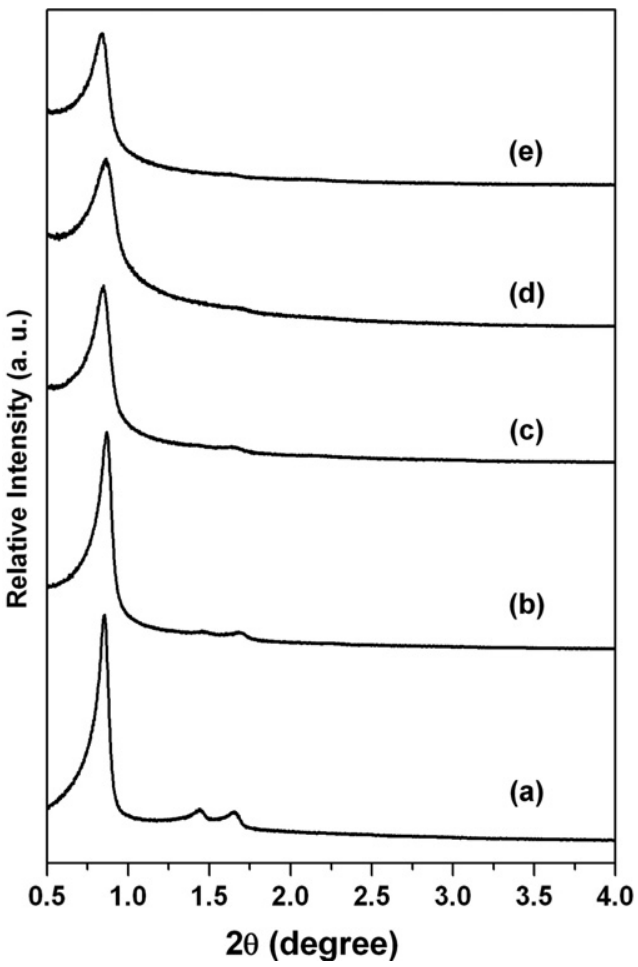

Fig. 1. X-ray powder diffraction patterns of mixed arenesulfonic acid with thiol-functionalized SBA-15 series: (a) $\mathrm{S} 15-\mathrm{Ar}_{-} \mathrm{SO}_{3} \mathrm{H}(10 \%)$, (b) $\mathrm{S} 15-\mathrm{Ar}-$ $\mathrm{SO}_{3} \mathrm{H}(10 \%)-\mathrm{SH}(2 \%)$, (c) $\mathrm{S} 15-\mathrm{Ar}_{-} \mathrm{SO}_{3} \mathrm{H} \quad(10 \%)-\mathrm{SH}(5 \%)$, (d) $\mathrm{S} 15-\mathrm{Ar}-$ $\mathrm{SO}_{3} \mathrm{H}(10 \%)-\mathrm{SH}(10 \%)$, and (e) $\mathrm{S} 15-\mathrm{Ar}_{-} \mathrm{SO}_{3} \mathrm{H}(10 \%)-\mathrm{SH}(15 \%)$

values, indicating the decrease in pore mouths and the heterogeneity of pore diameters. The BJH pore size distributions are shown in Fig. 2b. With the introduction of mercapto groups, the pore diameter decreases and a new peak appears at pore diameter around $36 \AA$.

The textural properties of the sulfonic acid and thiolfunctionized SBA-15 materials are summarized in Table 1. The unit cell $a_{\mathrm{o}}$ values of arenesulfonic acid and thiol dual-functionalized SBA-15 calculated from $d_{100}$ spacing of the extracted materials maintain in a narrow range of $117-121 \AA$, which are close to that of merely arenesulfonic acid-functionalized samples $\mathrm{S} 15-\mathrm{Ar}-\mathrm{SO}_{3} \mathrm{H}(5-15 \%)$ or propylsulfonic acid-functionalized sample S15-propyl$\mathrm{SO}_{3} \mathrm{H}(10 \%)$. As the loading of arenesulfonic acid was kept at $10 \%$, the surface area and pore volume of the mesoporous materials decrease gradually as the loading of mercapto groups increases. This indicates a filling of the pores by large amount of organic molecules anchored on the surfaces. It is also noticeable that the peak pore diameters of the dual-functionalized mesoporous materials decrease markedly to $36 \AA$ from $62 \AA$ for S15-Ar$\mathrm{SO}_{3} \mathrm{H}(10 \%)$. Moreover, this value is independent of the mercapto loading and the same as that of thiol-functionized SBA-15. Such a great shrinkage in pore diameter suggests that disulfide groups might be formed through oxidative condensation between two mercapto groups attaching on the walls. Similar phenomena probably also occurred on the dual-functionalized SBA-16 and 

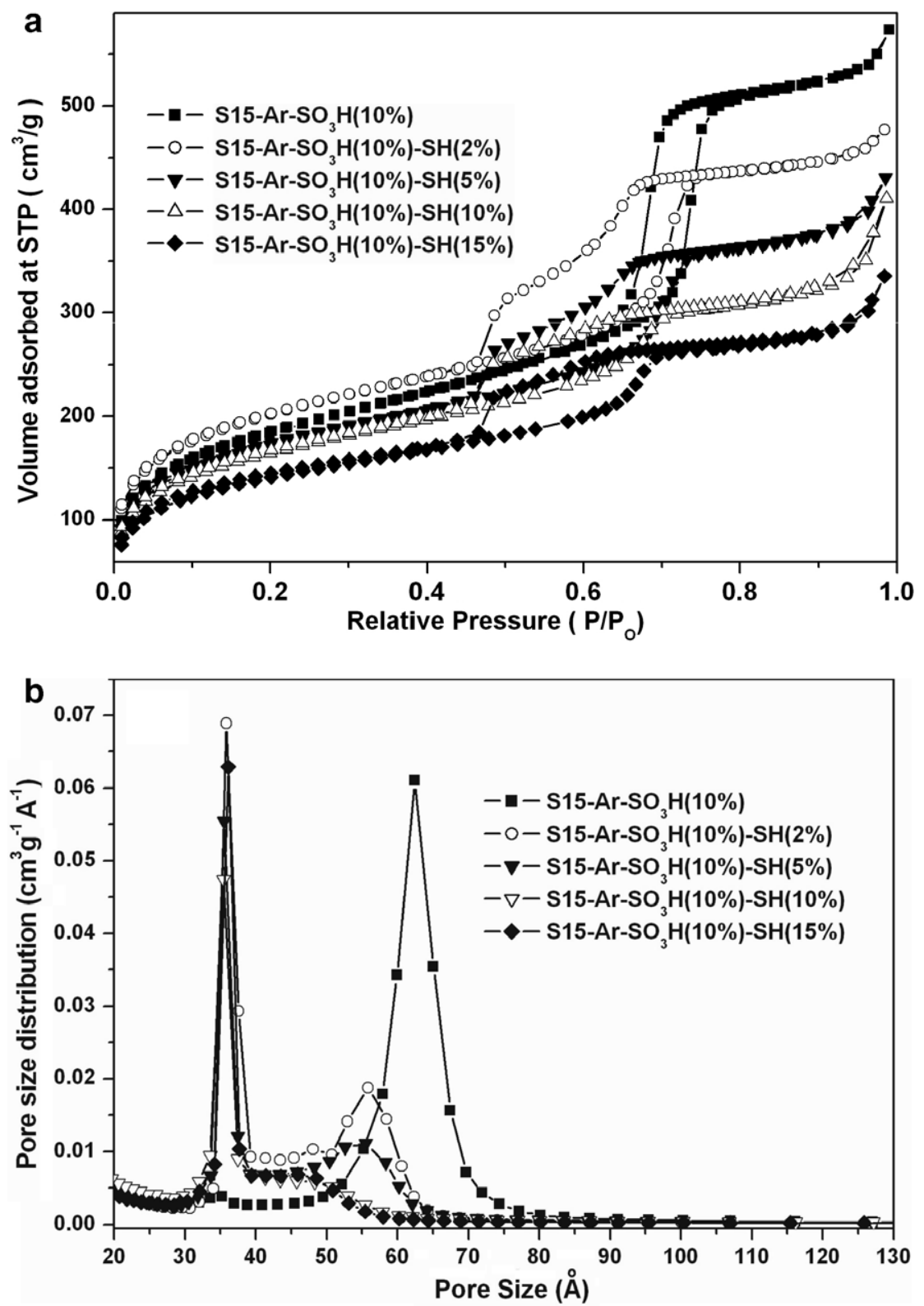

Fig. 2. (a) $\mathrm{N}_{2}$ adsorption-desorption isotherms and (b) BJH pore size distribution profiles of arenesulfonic acid and thiol dual-functionalized SBA-15

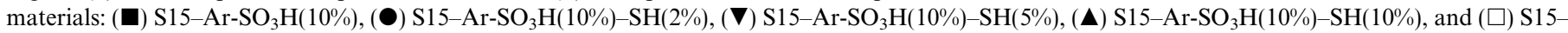
$\mathrm{Ar}-\mathrm{SO}_{3} \mathrm{H}(10 \%)-\mathrm{SH}(15 \%)$.

amorphous silica because their peak pore diameters were also in $35-36 \AA$. In contrast, relatively larger pore diameter of $56 \AA$ was observed for sulfonic acid and disulfide dualfunctionalized $\mathrm{S} 15-\mathrm{Ar}-\mathrm{SO}_{3} \mathrm{H}(10 \%)-\mathrm{S}-\mathrm{S}(10 \%)$, which was prepared with disulfide silane. These results imply that the pore diameters of mesoporous silica materials are reduced due to oxidative condensation between two mercapto groups on two MPTMS molecules during the assembly process of mesoporous silica.

The SEM photograph shows that most of the arenesulfonic acid and thiol dual-functionalized SBA-15 materials are in the rod shape of ca. $0.2 \mu \mathrm{m}$ in diameter and $1 \mu \mathrm{m}$ in length (Fig. 3a). The TEM micrographs confirm that the dual-functionalized SBA-15 materials contain well- ordered one-dimensional pore structure (Figs. 3b-d), similar to pure siliceous SBA-15. The pore diameters determined from TEM photographs are ca. $5 \mathrm{~nm}$, which is close to the BJH pore diameter.

Qualitative identification of the organic functional groups in the materials was performed by FTIR spectroscopy. Fig. 4 illustrates the FTIR spectrum of the SBA-15 material dual-functionalized with $10 \mathrm{~mol} \%$ CSPETES and $10 \mathrm{~mol} \%$ MPTMS in comparison to those of singly functionalized counterparts and pure siliceous SBA-15. Common to all samples are the bands around 1220, 1070, 794, and $471 \mathrm{~cm}^{-1}$ assigned to the typical $\mathrm{Si}-\mathrm{O}-\mathrm{Si}$ stretching and bending vibrations of condensed silica network and the peaks around $960 \mathrm{~cm}^{-1}$ corresponding to non-con- 
Table 1

Textural properties of functionalized SBA-15 materials

\begin{tabular}{|c|c|c|c|c|}
\hline Sample & $\begin{array}{l}a_{o} \\
(\AA)^{\mathrm{a}}\end{array}$ & $\begin{array}{l}S_{\mathrm{BET}} \\
\left(\mathrm{m}^{2} / \mathrm{g}\right)\end{array}$ & $\begin{array}{l}D_{\mathrm{p}} \\
(\AA)^{\mathrm{b}}\end{array}$ & $\begin{array}{l}V_{\mathrm{p}} \\
\left(\mathrm{cm}^{3} / \mathrm{g}\right)\end{array}$ \\
\hline $\mathrm{S} 15-\mathrm{Ar}-\mathrm{SO}_{3} \mathrm{H}(5 \%)$ & 118 & 710 & 67 & 0.96 \\
\hline $\mathrm{S} 15-\mathrm{Ar}-\mathrm{SO}_{3} \mathrm{H}(10 \%)$ & 120 & 655 & 62 & 0.83 \\
\hline $\mathrm{S} 15-\mathrm{Ar}-\mathrm{SO}_{3} \mathrm{H}(15 \%)$ & 125 & 543 & 64 & 0.60 \\
\hline $\mathrm{S} 15$-propyl- $\mathrm{SO}_{3} \mathrm{H}(10 \%)$ & 119 & 776 & 68 & 1.06 \\
\hline $\mathrm{S} 15-\mathrm{SH}(20 \%)$ & 100 & 472 & 36 & 0.38 \\
\hline S15-SH(20\%)_O3h & 104 & 427 & 36 & 0.37 \\
\hline $\mathrm{S} 15-\mathrm{Ar}_{-} \mathrm{SO}_{3} \mathrm{H}(10 \%)-\mathrm{SH}(2 \%)$ & 117 & 710 & 36 & 0.71 \\
\hline $\mathrm{S} 15-\mathrm{Ar}-\mathrm{SO}_{3} \mathrm{H}(10 \%)-\mathrm{SH}(5 \%)$ & 120 & 611 & 36 & 0.62 \\
\hline $\mathrm{S} 15-\mathrm{Ar}-\mathrm{SO}_{3} \mathrm{H}(10 \%)-\mathrm{SH}(10 \%)$ & 117 & 584 & 35 & 0.54 \\
\hline $\mathrm{S} 15-\mathrm{Ar}-\mathrm{SO}_{3} \mathrm{H}(10 \%)-\mathrm{SH}(15 \%)$ & 121 & 498 & 36 & 0.47 \\
\hline $\mathrm{S} 15-\mathrm{Ar}^{-} \mathrm{SO}_{3} \mathrm{H}(10 \%)-\mathrm{S}-\mathrm{S}(10 \%)$ & 117 & 622 & 56 & 0.67 \\
\hline $\mathrm{S} 16-\mathrm{Ar}-\mathrm{SO}_{3} \mathrm{H}(10 \%)-\mathrm{SH}(15 \%)$ & $116^{\mathrm{c}}$ & 501 & 35 & 0.67 \\
\hline $\mathrm{SiO}_{2}-\mathrm{Ar}-\mathrm{SO}_{3} \mathrm{H}(10 \%)-\mathrm{SH}(15 \%)$ & - & 437 & 36 & 0.35 \\
\hline
\end{tabular}

${ }^{\mathrm{a}} a_{\mathrm{o}}=2 d_{100} / \sqrt{3}$.

${ }^{\mathrm{b}}$ Calculated from the desorption branch.

c $d_{110}$ value of $\operatorname{Im} 3 m$.

densed $\mathrm{Si}-\mathrm{OH}$ groups $[31,32]$. The broad band around $3400 \mathrm{~cm}^{-1}$ and the strong peak around $1630 \mathrm{~cm}^{-1}$ are due to the stretching and bending vibrations of adsorbed $\mathrm{H}_{2} \mathrm{O}$. In comparison to the spectrum of pure siliceous SBA-15, the arenesulfonic acid functionalized materials have additional peaks at 566 and $698 \mathrm{~cm}^{-1}$ with medium intensity and two weak peaks at 1420 and $1500 \mathrm{~cm}^{-1}$, as shown in the enlarged portions of the spectra in Fig. $4 \mathrm{~b}$. The low wave-number peaks are assigned to the out-ofplane bending of the para di-substituted aromatic ring as well as the bending vibration of the sulfonic acid group, and the two weak peaks at high wave-numbers are bending vibrations of $\mathrm{C}-\mathrm{H}$ in aromatic rings [31]. These results confirm the incorporation of arenesulfonic acid groups into the silica materials. The peaks corresponding to the $\mathrm{S}=\mathrm{O}$ stretching vibrations appear at ca. $1000 \mathrm{~cm}^{-1}$ as a shoulder of the strong absorbance of $\mathrm{Si}-\mathrm{O}-\mathrm{Si}$ stretch in 1000 $1130 \mathrm{~cm}^{-1}$ range and that of $\mathrm{Si}-\mathrm{C}$ stretch in 1200 $1250 \mathrm{~cm}^{-1}$ range. On the other hand, a broad absorbance around $2850-3000 \mathrm{~cm}^{-1}$ and a weak peak around 1450 $1470 \mathrm{~cm}^{-1}$ are attributed to the stretching and bending vibration of methylene groups, further confirming the incorporation of organic groups. No clear information about the presence of thiol S-H species was obtained from IR studies, since the $\mathrm{S}-\mathrm{H}$ stretching vibration at about $2575 \mathrm{~cm}^{-1}$ was usually very weak and difficult to detect [33].

Thermogravimetric (TG) analysis was carried out on the ethanol extracted materials to determine the amount of organic groups incorporated into SBA-15, and the results are shown in Fig. 5. For the sample merely functionalized with $10 \%$ arenesulfonic acid, the TG profile has very clear two steps weight losses. The first weight loss of ca. 16\% at temperatures lower than $100^{\circ} \mathrm{C}$, corresponding to the desorption of physically adsorbed water. The second weight loss of $17 \%$ at $450-650{ }^{\circ} \mathrm{C}$ is due to the decomposition of arenesulfonic acid groups [17]. As mercapto groups were also introduced, additional weight losses were observed in between these two steps. The weight loss near $350{ }^{\circ} \mathrm{C}$ is attributed to the decomposition of mercaptopropyl groups [10], while that in the temperature range of 150 $200{ }^{\circ} \mathrm{C}$ is ascribed to the removal of the surfactant P123 residues. It is also noticed that the weight loss below
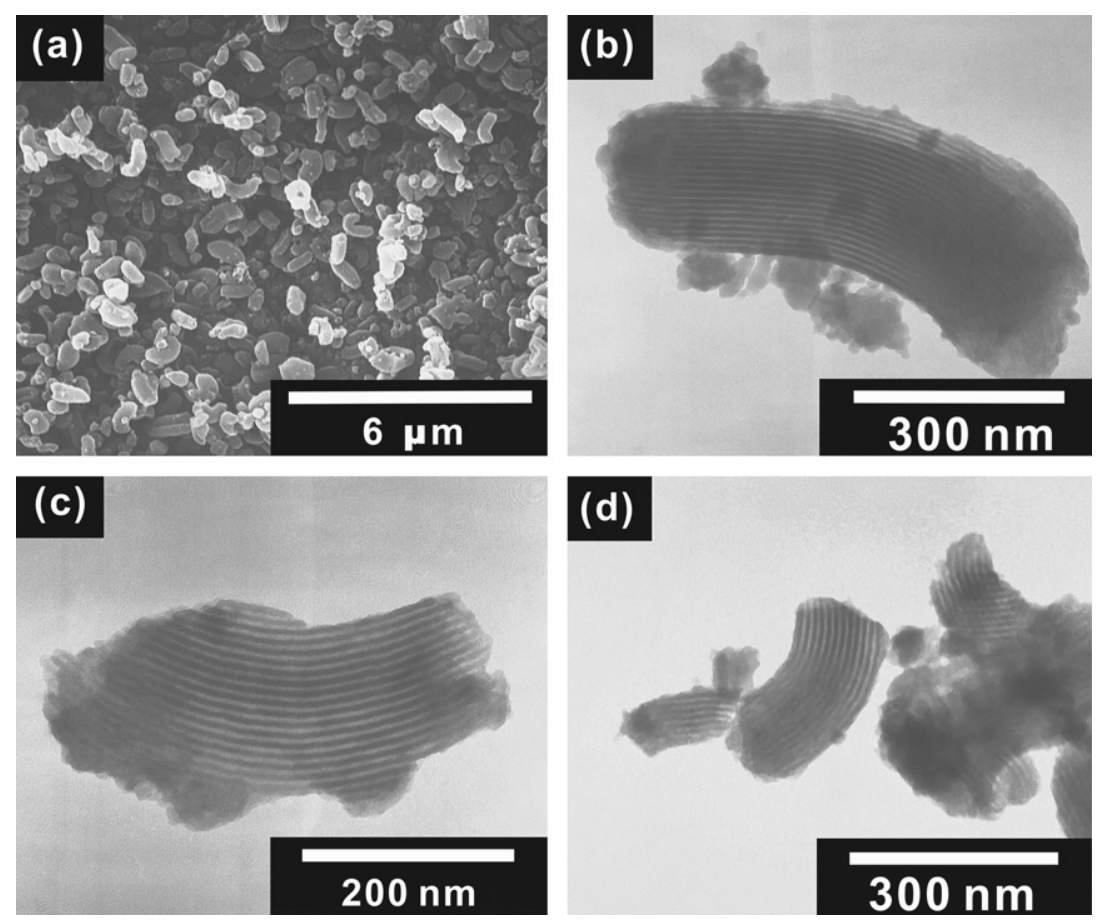

Fig. 3. SEM photograph of (a) $\mathrm{S} 15-\mathrm{Ar}_{-} \mathrm{SO}_{3} \mathrm{H}(10 \%)-\mathrm{SH}(2 \%)$ and TEM photographs of (b) $\mathrm{S} 15-\mathrm{Ar}-\mathrm{SO}_{3} \mathrm{H}(10 \%)-\mathrm{SH}(2 \%),(\mathrm{c}) \mathrm{S} 15-\mathrm{Ar}-\mathrm{SO} \mathrm{O}_{3} \mathrm{H}(10 \%)-$ $\mathrm{SH}(5 \%)$, and (d) $\mathrm{S} 15-\mathrm{Ar}_{-} \mathrm{SO}_{3} \mathrm{H}(10 \%)-\mathrm{SH}(10 \%)$. 

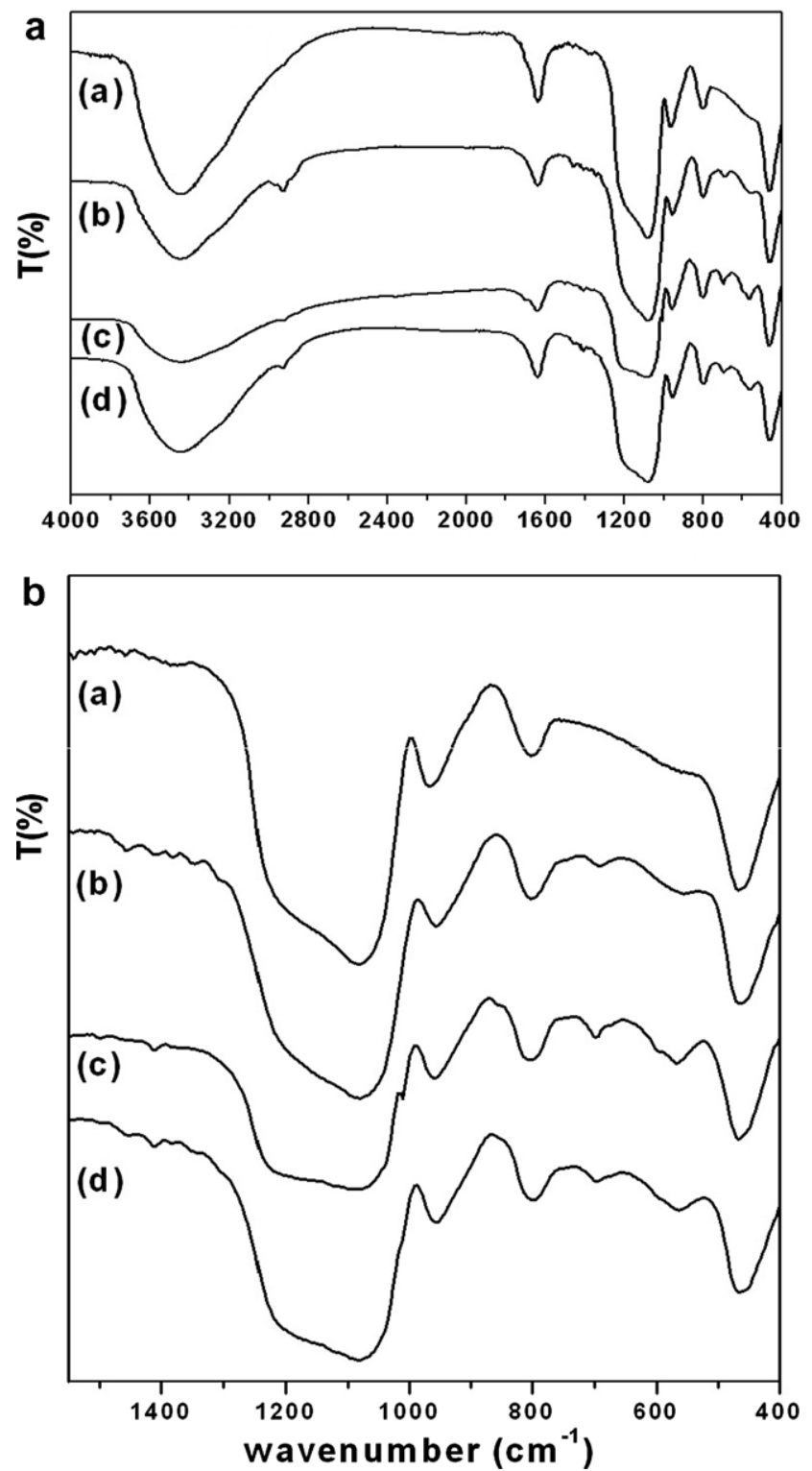

Fig. 4. FT-IR spectra of (a) pure siliceous SBA-15 and functionalized SBA-15: (b) $\mathrm{S} 15-\mathrm{SH}(20 \%)$ (c) $\mathrm{S} 15-\mathrm{Ar}^{-} \mathrm{SO}_{3} \mathrm{H}(10 \%)$ and (d) $\mathrm{S} 15-\mathrm{Ar}-$ $\mathrm{SO}_{3} \mathrm{H}(10 \%)-\mathrm{SH}(10 \%)$.

$100{ }^{\circ} \mathrm{C}$ decreases as the amount of MPTM introduced in the synthesis gels increases. That is due to the hydrophobic character of the mercaptopropyl groups.

The elemental analysis and acid capacities of sulfonic acid and thiol functionized SBA-15 materials are shown in Table 2. For the merely arenesulfonic acid-functionalized SBA-15 (entries 1-3), both the acid capacity and the $\mathrm{S}$ content increase with the amount of CSPETES introduced in the synthesis solution. However, the incorporation ratio of silane into the SBA-15 materials decreases with the CSPETES loading, implying that CSPETES is more difficult than TEOS to condensate onto the silica framework. It is also noticeable that the acid capacities determined by $\mathrm{NaOH}$ titration of merely arenesulfonic acid-functionalized SBA-15 are very close to the S contents determined by EA, confirming that the chlorosulfonyl moieties in CSPETES precursors was completely in situ hydrolyzed to sulfonic acid under the synthesis condition. Moreover, all the arenesulfonic acid groups in the samples should locate on the surfaces of the pore walls and were easily accessed by the $\mathrm{Na}^{+}$ions.

For the merely thiol-functionalized SBA-15 (entry 5), the incorporating ratio of sulfur is greater than $100 \%$. This implies that MPTMS is more easily condensed than TEOS onto the silica framework. The $\mathrm{S}$ content and incorporating ratio decrease after the sample was oxidized in $\mathrm{H}_{2} \mathrm{O}_{2}$ for $3 \mathrm{~h}$ (entry 6), indicating that a portion of the organic moiety was cleaved during the oxidation process, which was also reported in the literature [24,25].

For the dual-functionalized SBA-15 materials (entries 7-10) in which the amount of CSPETES introduced in the synthesis solution was kept at a constant value of $10 \mathrm{~mol} \%$ of TEOS, the acid capacity of the solids decreases in general with the increase in mercapto loading. These results indicate that CSPETES and MPTMS are competitive in condensation onto the silica framework. When the MPTMS/CSPETES molar ratio in the synthesis mixture was less than 1, the condensation of CSPETES onto the silica framework was found to be much favorable to that of MPTMS. In contrast, higher incorporating ratios of mercapto groups than that of sulfonyl groups were observed when the MPTMS/CSPETES molar ratio was equal to or greater than 1 .

$\mathrm{X}$-ray absorption near-edge structure (XANES) spectroscopy is very sensitive to the electronic structure, oxidation state, and local symmetry of the absorbing site compared to classical methods of chemical characterization of sulfur-containing compounds. Sulfur K-edge XANES spectroscopy has been effectively used to study sulfur speciation in various natural systems [34-36]. The increase in absorption energy $\left(E_{k}\right)$ and intensity of the white line (i.e., main adsorption peak) with increasing formal oxidation state allows us to identify and quantify the different sulfur species present in the sample [35]. The sulfur K-edge XANES spectra of the thiol and disulfide standards as well as the arenesulfonic acid and thiol dual-functionalized samples are shown in Fig. 6. The MPTMS spectrum is characterized by a strong absorption resonance at $2472.3 \mathrm{eV}$ (Fig. 6a). It is assigned to the sulfur $1 \mathrm{~s} \rightarrow \sigma^{*}$ $(\mathrm{S}-\mathrm{H})$ and $1 \mathrm{~s} \rightarrow \sigma^{*}(\mathrm{C}-\mathrm{S})$ transitions [37,38]. Both have about the same energies and therefore cannot be distinguished. In addition, a shoulder appeared at about $2475.6 \mathrm{eV}$ corresponds to the Rydberg transition for compounds containing S-H bonds [39]. The spectrum of propyl disulfide shows the typical white line structure of C-S-S-C segment (Fig. 6b). The first peak at the low energy $(2471.4 \mathrm{eV})$ is assigned to the sulfur $1 \mathrm{~s} \rightarrow \sigma^{*}(\mathrm{~S}-\mathrm{S})$ transition while a second peak occurring at higher energy $(2473.0 \mathrm{eV})$ is associated with sulfur $1 \mathrm{~s} \rightarrow \sigma^{*}(\mathrm{C}-\mathrm{S})$ transition $[37,38]$.

The sulfur K-edge XANES spectra of arenesulfonic acid and thiol dual-functionalized SBA-15 show a prominent 


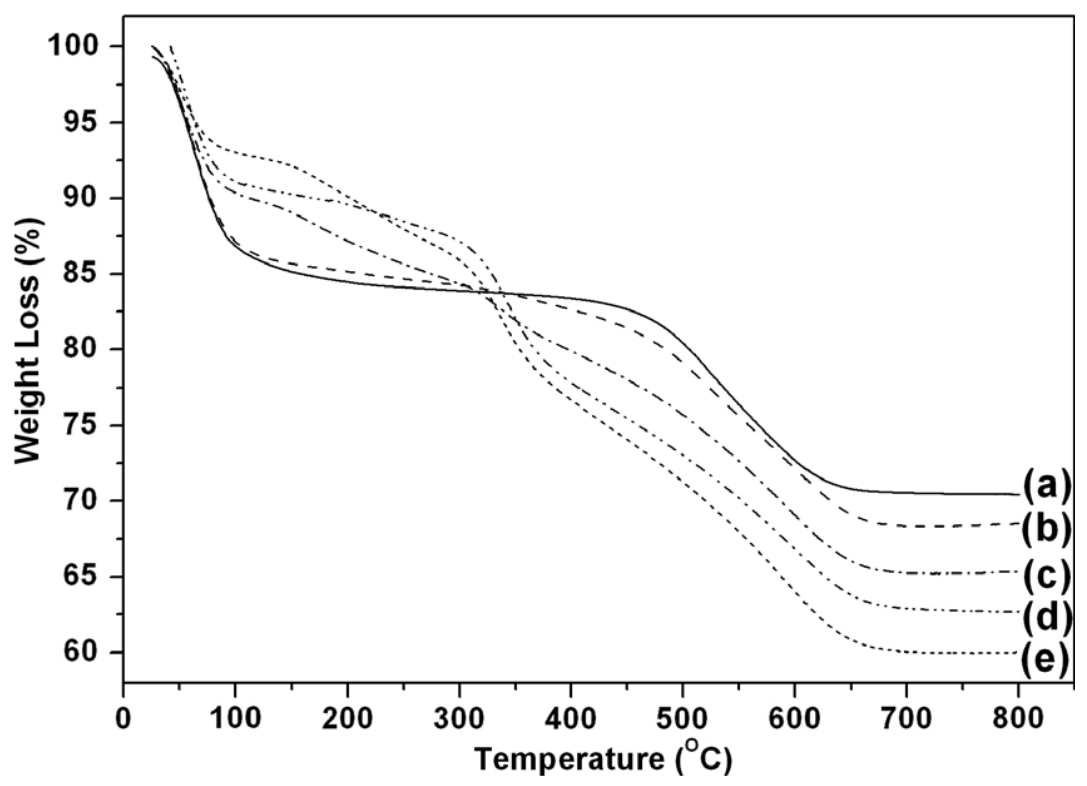

Fig. 5. TGA profiles of arenesulfonic acid and thiol dual-functionalized SBA-15 materials: (a) $\mathrm{S} 15-\mathrm{Ar}_{-} \mathrm{SO}_{3} \mathrm{H}(10 \%)$, (b) $\mathrm{S} 15-\mathrm{Ar}-\mathrm{SO}{ }_{3} \mathrm{H}(10 \%)-\mathrm{SH}(2 \%)$, (c) $\mathrm{S} 15-\mathrm{Ar}_{-} \mathrm{SO}_{3} \mathrm{H}(10 \%)-\mathrm{SH}(5 \%)$, (d) $\mathrm{S} 15-\mathrm{Ar}_{-} \mathrm{SO}_{3} \mathrm{H}(10 \%)-\mathrm{SH}(10 \%)$, and (e) $\mathrm{S} 15-\mathrm{Ar}^{-} \mathrm{SO}_{3} \mathrm{H}(10 \%)-\mathrm{SH}(15 \%)$.

Table 2

Acid capacities and elemental analysis results of functionalized mesoporous silica materials

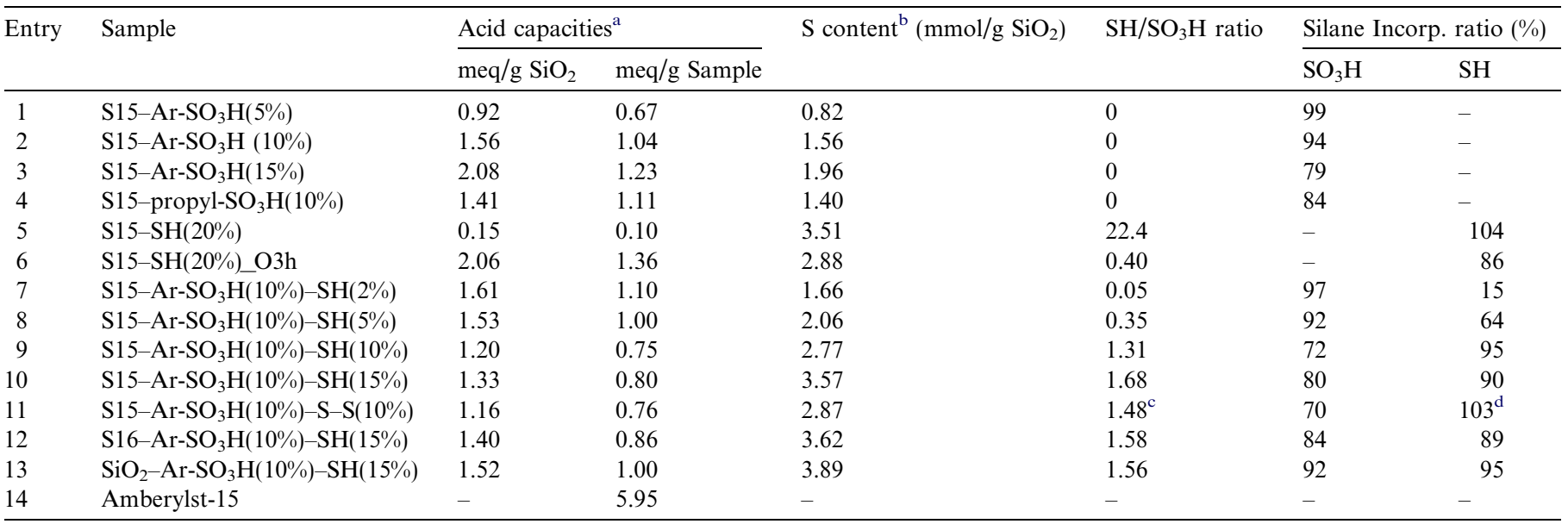

${ }^{\mathrm{a}}$ From $\mathrm{NaOH}$ titration.

${ }^{\mathrm{b}}$ From element analysis.

c $-\mathrm{S}-/ \mathrm{SO}_{3} \mathrm{H}$ ratio.

${ }^{\mathrm{d}}$ Incorporation ratio of $-\mathrm{S}-\mathrm{S}$ -

peak at $2480.4 \mathrm{eV}$. This peak was also observed for merely arenesulfonic acid-functionalized $\mathrm{S} 15-\mathrm{Ar}_{-} \mathrm{SO}_{3} \mathrm{H}(10 \%)$ sample, and it corresponds to sulfur atom in +5 oxidation state [40]. In the lower energy region, two peaks were observed at 2471.6 and $2473 \mathrm{eV}$ for sample $\mathrm{S} 15-\mathrm{Ar}_{-} \mathrm{SO}_{3} \mathrm{H}(10 \%)-$ $\mathrm{SH}(5 \%)$. These peaks are the characteristic white line structure of disulfide $\mathrm{C}-\mathrm{S}-\mathrm{S}-\mathrm{C}$ segment. As the amount of MPTMS introduced in the synthesis solution increases, the intensity of these two peaks increases but they merge closer to $2472 \mathrm{eV}$, which is the characteristic peak for mercapto $\mathrm{S}-\mathrm{H}$ groups. These results indicate that the mercapto groups on MPTMS are easily oxidized to disulfide groups during the silica condensation process. As the concentra- tion of MPTMS increased, however, more mercapto groups were retained in the dual-functionalized mesoporous products.

The sulfur K-edge XANES spectra of merely thiol-functionalized SBA-15 and its $\mathrm{H}_{2} \mathrm{O}_{2}$ oxidized derivative were shown in Figs. $6 \mathrm{~g}$ and $\mathrm{h}$. The $\mathrm{S} 15-\mathrm{SH}(20 \%)$ sample shows predominantly the peak corresponding to $\mathrm{S}-\mathrm{H}$ at $2472 \mathrm{eV}$. However, a very weak peak originated from the sulfonic acid groups can also be seen around $2479.6 \mathrm{eV}$. This result implies that a small amount of mercapto groups was oxidized to sulfonic acid during the preparation process even though no oxidizing agent was purposely added. After S15-SH $(20 \%)$ was oxidized with $\mathrm{H}_{2} \mathrm{O}_{2}$ for $3 \mathrm{~h}$, the sulfonic 


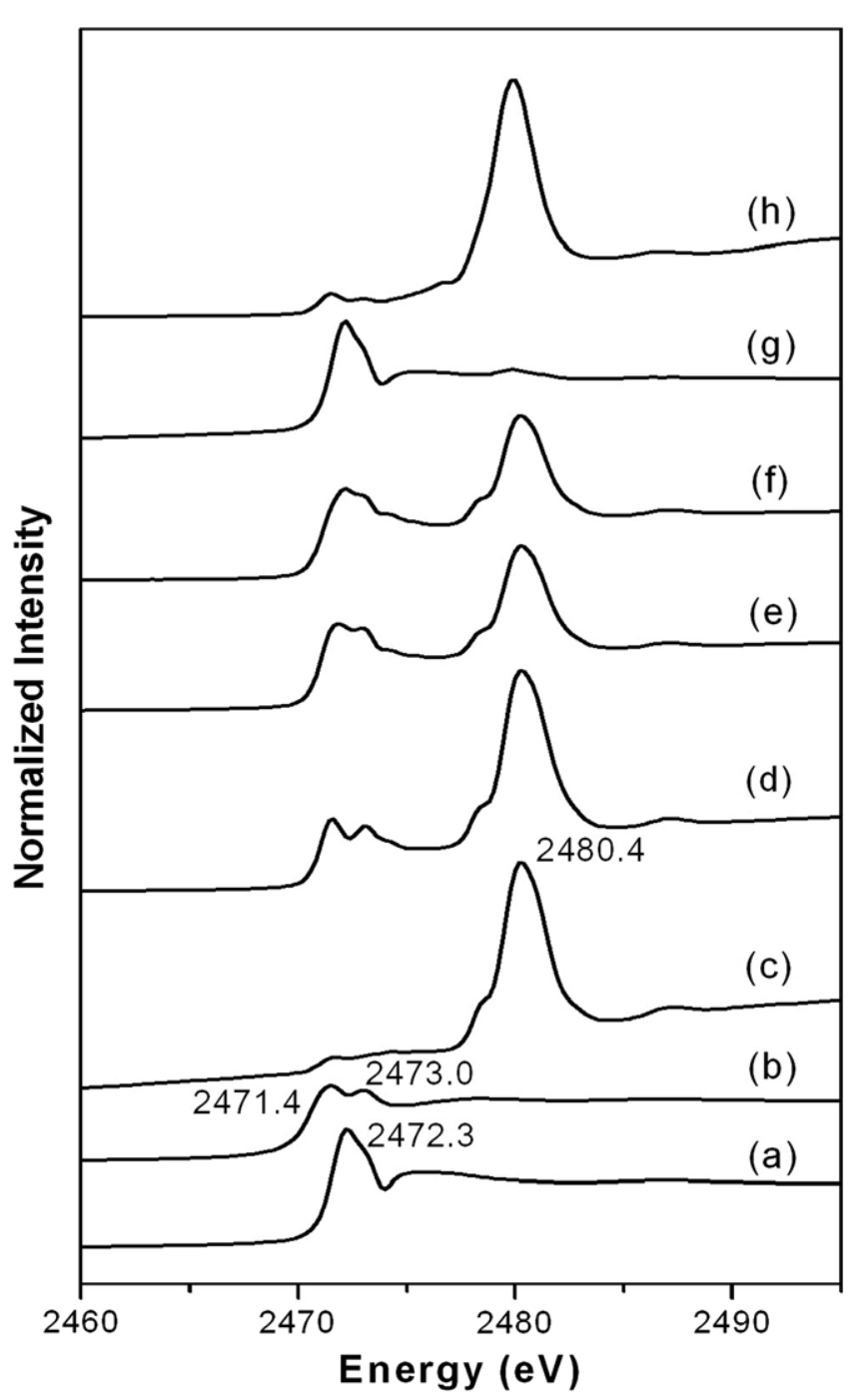

Fig. 6. Sulfur K-edge XANES spectra of standards: (a) MPTMS, (b) propyl disulfide, and those of functionalized SBA-15 materials: (c) S15- $\mathrm{Ar}_{-} \mathrm{SO}_{3} \mathrm{H}(10 \%)-\mathrm{SH}(2 \%)$, (d) $\mathrm{S} 15-\mathrm{Ar}_{-} \mathrm{SO}_{3} \mathrm{H}(10 \%)-\mathrm{SH}(5 \%)$, (e) $\mathrm{S} 15-$ $\mathrm{Ar}-\mathrm{SO}_{3} \mathrm{H}(10 \%)-\mathrm{SH}(10 \%)$, (f) $\mathrm{S} 15-\mathrm{Ar}_{-} \mathrm{SO}_{3} \mathrm{H}(10 \%)-\mathrm{SH}(15 \%)$, (g) $\mathrm{S} 15-$ $\mathrm{SH}(20 \%)$, and (h) S15-SH(20\%)_3 h.

acid peak becomes predominant. However, there are still weak peaks at 2471.6 and $2473 \mathrm{eV}$ in the low energy region, indicating that a small amount of disulfide groups was formed on sample S15-SH(20\%)_O3h.

\subsection{Catalytic reactions}

The arenesulfonic acid and thiol functionalized SBA-15 materials were used as catalysts in condensation of phenol and acetone to form bisphenol-A at $85^{\circ} \mathrm{C}$. The results were compared with the commercial Amberlyst-15 and various acid-functionalized porous materials as given in Table 3 . Over the merely arenesulfonic acid-functionalized SBA-15 silica (entries 1-3), the phenol conversion and $p, p^{\prime}$-bisphenol-A selectivity were found to increase with the acid loading. Several reaction by-products are shown in Scheme 1 [41]. The $o, p^{\prime}$-bisphenol-A is the major one, and others are the chroman derivatives formed by the reactions of phenol with mesityl oxide or $o, p^{\prime}$-bisphenol-A with acetone. The turnover numbers (TON) of $p, p^{\prime}$-bisphenol-A were in the range of 22-24 and independent of the acid capacity of the catalysts, implying that all the arenesulfonic acid groups incorporated in the mesoporous silica were accessible to the reactants. Comparatively, the ionexchange resin Amberlyst-15 (entry 15), which has more than five times higher in acid capacity (5.95 vs. $0.67-$ $1.23 \mathrm{mmol} \mathrm{H}^{+} / \mathrm{g}$ in Table 2), gave higher phenol conversion and $p, p^{\prime} / o, p^{\prime}$-bisphenol-A ratio but much lower $p, p^{\prime}$ bisphenol-A TON (6.0 vs. 22-24). The low TON of Amberlyst-15 should be due to the low surface area and the inaccessibility of the inner acid sites in resin by the reactants.

Interesting phenomena were observed when mercapto groups were co-functionalized with arenesulfonic acid (entries 7-10). Dramatic improvement in catalytic activity and selectivity of $p, p^{\prime}$-bisphenol-A was seen even just a small amount of MPTMS was introduced. Although the acid capacities of all the dual-functionalized samples were close to or even lower than the merely arenesulfonic acid functionalized $\mathrm{S} 15-\mathrm{Ar}-\mathrm{SO}_{3} \mathrm{H}(10 \%)$ catalyst, the phenol conversions were more than double and $p, p^{\prime}$-bisphenol-A selectivities were raised from $\sim 70 \%$ to greater than $91 \%$. Moreover, the TONs increased to 65-104. To the best of our knowledge, the $p, p^{\prime}$-bisphenol-A TONs of greater than 100 reported in this Table are the highest values reported for this catalytic reaction. The optimal selectivity toward $p, p^{\prime}$-bisphenol-A of $96 \%$ was obtained when the mercapto loading in the catalyst was increased to $10-15 \%$ or the $\mathrm{SH} / \mathrm{SO}_{3} \mathrm{H}$ ratio was around 1.3-1.6 (Table 2). These results indicate that the mercapto groups should act as a potent promoter in the formation of bisphenol-A. Moreover, the sulfur K-edge XANES spectra showed that a large portion of the mercapto groups was oxidized to disulfide during the synthesis process, especially for the samples with low thiol contents. Therefore, the possible contribution of disulfide in promoting the catalytic activity cannot be ruled out.

The catalytic activities of arenesulfonic acid functionalized SBA-15 materials in condensation of phenol and acetone were also compared with those of several other porous acid catalysts. Entry 4 in Table 3 shows that the propylsulfonic acid-functionalized SBA-15 gives similar $p, p^{\prime}$-bisphenol-A selectivity (ca. 69\%) as that of merely arenesulfonic acid functionalized SBA-15 but with much lower phenol conversion and TON. These results are attributed to the weaker acidic strength of the propylsulfonic acid group in comparison to the arenesulfonic acid. On the other hand, very high selectivities and TONs of $p, p^{\prime}$-bisphenol-A were obtained over thiol-functionized SBA-15 (entry 5) and that oxidized with $\mathrm{H}_{2} \mathrm{O}_{2}$ for $3 \mathrm{~h}$ (entry 6). Since the sulfur K-edge XANES spectra showed that a small portion of mercapto groups was oxidized to sulfonic acid on $\mathrm{S} 15-\mathrm{SH}(20 \%)$ while some disulfide groups in addition to sulfonic acid were present on $\mathrm{S} 15-\mathrm{SH}(20 \%) \_3 \mathrm{~h}$, these 
Table 3

Catalytic synthesis of bisphenol-A over sulfonic acid-functionalized mesoporous materials ${ }^{\mathrm{a}}$

\begin{tabular}{|c|c|c|c|c|c|c|}
\hline \multirow[t]{2}{*}{ Entry } & \multirow[t]{2}{*}{ Catalyst } & \multirow[t]{2}{*}{ Phenol Cov. $(\%)$} & \multicolumn{2}{|c|}{ Selectivity $(\%)$} & \multirow{2}{*}{$\frac{p, p^{\prime}}{o, p^{\prime}}$ ratio } & \multirow[t]{2}{*}{$\mathrm{TON}^{\mathrm{b}}$} \\
\hline & & & $p, p^{\prime}-\mathrm{BPA}$ & $o, p$-BPA & & \\
\hline 1 & $\mathrm{~S} 15-\mathrm{Ar}-\mathrm{SO}_{3} \mathrm{H}(5 \%)$ & 10 & 65 & 24 & 2.7 & 24 \\
\hline 3 & $\mathrm{~S} 15-\mathrm{Ar}-\mathrm{SO}_{3} \mathrm{H}(15 \%)$ & 15 & 75 & 16 & 4.6 & 23 \\
\hline 4 & $\mathrm{~S} 15-$ propyl- $\mathrm{SO}_{3} \mathrm{H}(10 \%)$ & 7 & 69 & 20 & 3.4 & 12 \\
\hline 5 & $\mathrm{~S} 15-\mathrm{SH}(20 \%)$ & 3 & 95 & 4.9 & 19 & 74 \\
\hline 6 & $\mathrm{~S} 15-\mathrm{SH}(20 \%) \_\mathrm{O} 3 \mathrm{~h}$ & 15 & 86 & 9.4 & 9.2 & 24 \\
\hline 9 & $\mathrm{~S} 15-\mathrm{Ar}^{-\mathrm{SO}_{3} \mathrm{H}(10 \%)-\mathrm{SH}(10 \%)}$ & 33 & 96 & 3.5 & 27 & 104 \\
\hline 10 & $\mathrm{~S} 15-\mathrm{Ar}-\mathrm{SO}_{3} \mathrm{H}(10 \%)-\mathrm{SH}(15 \%)$ & 33 & 96 & 3.1 & 31 & 100 \\
\hline 11 & $\mathrm{~S} 15-\mathrm{Ar}-\mathrm{SO}_{3} \mathrm{H}(10 \%)-\mathrm{S}-\mathrm{S}(10 \%)$ & 26 & 91 & 7.3 & 13 & 79 \\
\hline 12 & $\mathrm{~S} 15-\mathrm{Ar}-\mathrm{SO}_{3} \mathrm{H}(10 \%)+\mathrm{S} 15-\mathrm{SH}\left(20^{\circ}\right)^{\mathrm{c}}$ & 16 & 77 & 14 & 5.6 & 30 \\
\hline 13 & $\mathrm{~S} 16-\mathrm{Ar}-\mathrm{SO}_{3} \mathrm{H}(10 \%)-\mathrm{SH}(15 \%)$ & 38 & 95 & 3.7 & 26 & 107 \\
\hline 14 & $\mathrm{SiO}_{2}-\mathrm{Ar}-\mathrm{SO}_{3} \mathrm{H}(10 \%)-\mathrm{SH}(15 \%)$ & 14 & 88 & 9.5 & 9.2 & 30 \\
\hline
\end{tabular}

${ }^{\mathrm{a}}$ Reaction condition: $85^{\circ} \mathrm{C}, 24 \mathrm{~h} ; 0.1 \mathrm{~g}$ catalyst, $4.7 \mathrm{~g}$ phenol, $0.58 \mathrm{~g}$ acetone (phenol:acetone molar ratio $=5: 1$ ).

${ }^{\mathrm{b}}$ Mol of $p, p^{\prime}$-bisphenol-A/ mol of active site in $24 \mathrm{~h}$.

${ }^{c}$ A physical mixture of $0.1 \mathrm{~g} \mathrm{~S} 15-\mathrm{Ar}^{-} \mathrm{SO}_{3} \mathrm{H}(10 \%)$ and $0.05 \mathrm{~g} \mathrm{~S} 15-\mathrm{SH}(20 \%)$.

${ }^{\mathrm{d}}$ Regenerated catalyst.

results suggest that the high selectivities and TON of $p$, $p^{\prime}$-bisphenol-A are due to the co-existence of both propylsulfonic acid and thiol (or disulfide).

The promotion effect of disulfide groups was examined by carried out condensation of phenol and acetone over SBA-15 dual-functionalized with disulfide and arenesulfonic acid. Entry 11 shows the selectivities and TON of $p, p^{\prime}$-bisphenol-A over $\mathrm{S} 15-\mathrm{Ar}-\mathrm{SO}_{3} \mathrm{H}(10 \%)-\mathrm{S}-\mathrm{S}(10 \%)$ are $90.9 \%$ and 78.6 , respectively. The high selectivity and TON confirm that disulfide groups also can promote $p, p^{\prime}$-bisphenol-A formation. However, its promoting efficiency is slightly lower than that of mercapto groups since the selectivity and TON of $p, p^{\prime}$-bisphenol-A over S15-Ar$\mathrm{SO}_{3} \mathrm{H}(10 \%)-\mathrm{S}-\mathrm{S}(10 \%)$ are slightly lower than those over $\mathrm{S} 15-\mathrm{Ar}-\mathrm{SO}_{3} \mathrm{H}(10 \%)-\mathrm{SH}(10 \%)$ or $\mathrm{S} 15-\mathrm{Ar}^{-} \mathrm{SO}_{3} \mathrm{H}(10 \%)-$ $\mathrm{SH}(5 \%)$.

The proposed mechanism for bisphenol-A formation over acid and mercapto dual-functionalized materials is similar to that reported in Refs. $[26,27]$ as shown in Scheme 2 . The mercapto group is suggested to form carbocation intermediates through nucleophilic attack on the protonated acetone followed by dehydration. The nucleophilic attack of the carbocations by phenol should be favorable to protonated acetone, and positive charged sulfur intermediates are formed. The reaction rate could further increase by nucleophilic attack of the positive charged sulfur intermediates by second phenol. Moreover, the positive charged sulfur intermediates also play steric hindrance and affect the approach of phenol. As a result, the selectivity toward $p, p^{\prime}$-bisphenol-A significantly increases on the acid catalysts co-functionalized with thiol. Similar mechanism was proposed for the reaction over acid and disulfide dual-functionalized materials as shown in Schemes 3. The disulfide instead of thiol is proposed to attack on the protonated acetone and form positive charged sulfur intermediates. The subsequently nucleophilic attack of the $\alpha$-carbon next to the positive charged sulfur by phenol leads to bisphenolA formation. Again, the selectivity of $p, p^{\prime}$-bisphenol-A is increased due to the steric hindrance of the intermediates.

The necessity of the acid sites and the thiol/disulfide sites in proximity was investigated by using a physical mixture of $0.1 \mathrm{~g}$ of $\mathrm{S} 15-\mathrm{Ar}_{-} \mathrm{SO}_{3} \mathrm{H}(10 \%)$ and $0.05 \mathrm{~g} \mathrm{~S} 15-\mathrm{SH}(20 \%)$ as the catalyst in condensation of phenol and acetone. The acid capacity and total sulfur content of this admixture were close to those of dual-functionalized S15-Ar$\mathrm{SO}_{3} \mathrm{H}(10 \%)-\mathrm{SH}(15 \%)$. Entry 12 shows that the phenol conversion over the admixture was much lower than that of dual-functionalized $\mathrm{S} 15-\mathrm{Ar}_{-} \mathrm{SO}_{3} \mathrm{H}(10 \%)-\mathrm{SH}(15 \%)$ and just slightly higher than that of pure $\mathrm{S} 15-\mathrm{Ar}-\mathrm{SO}_{3} \mathrm{H}(10 \%)$ catalyst (Entry 2). Moreover, the selectivity and TON of $p, p^{\prime}$ bisphenol-A over the admixture was lower than that of dual-functionalized $\mathrm{S} 15-\mathrm{Ar}_{-} \mathrm{SO}_{3} \mathrm{H}(10 \%)-\mathrm{SH}(15 \%)$. These results confirm the proposed mechanisms in which the thiol/disulfide sites should not be far away from the acid sites in order to achieve the promoting effect.

For the purpose of understanding the influence of pore structure of mesoporous silica on the catalytic activity, silica containing $10 \%$ arenesulfonic acid and $15 \%$ mercapto groups of SBA-16 cubic structure or amorphous gel was also synthesized using F127 $\left(\mathrm{EO}_{106} \mathrm{PO}_{70} \mathrm{EO}_{106}\right)$ as template or without template, respectively. Sample S16-Ar$\mathrm{SO}_{3} \mathrm{H}(10 \%)-\mathrm{SH}(15 \%)$ of SBA-16 cubic structure showed similar catalytic activity as that of dual functionalized SBA-15 catalysts (entry 13), while amorphous $\mathrm{SiO}_{2}-\mathrm{Ar}$ $\mathrm{SO}_{3} \mathrm{H}(10 \%)-\mathrm{SH}(15 \%)$ gave relatively low conversion of phenol and slightly lower $p, p^{\prime}$-bisphenol-A selectivity (entry 14). These results demonstrate the importance of ordered mesopores in facilitating the diffusion of the 

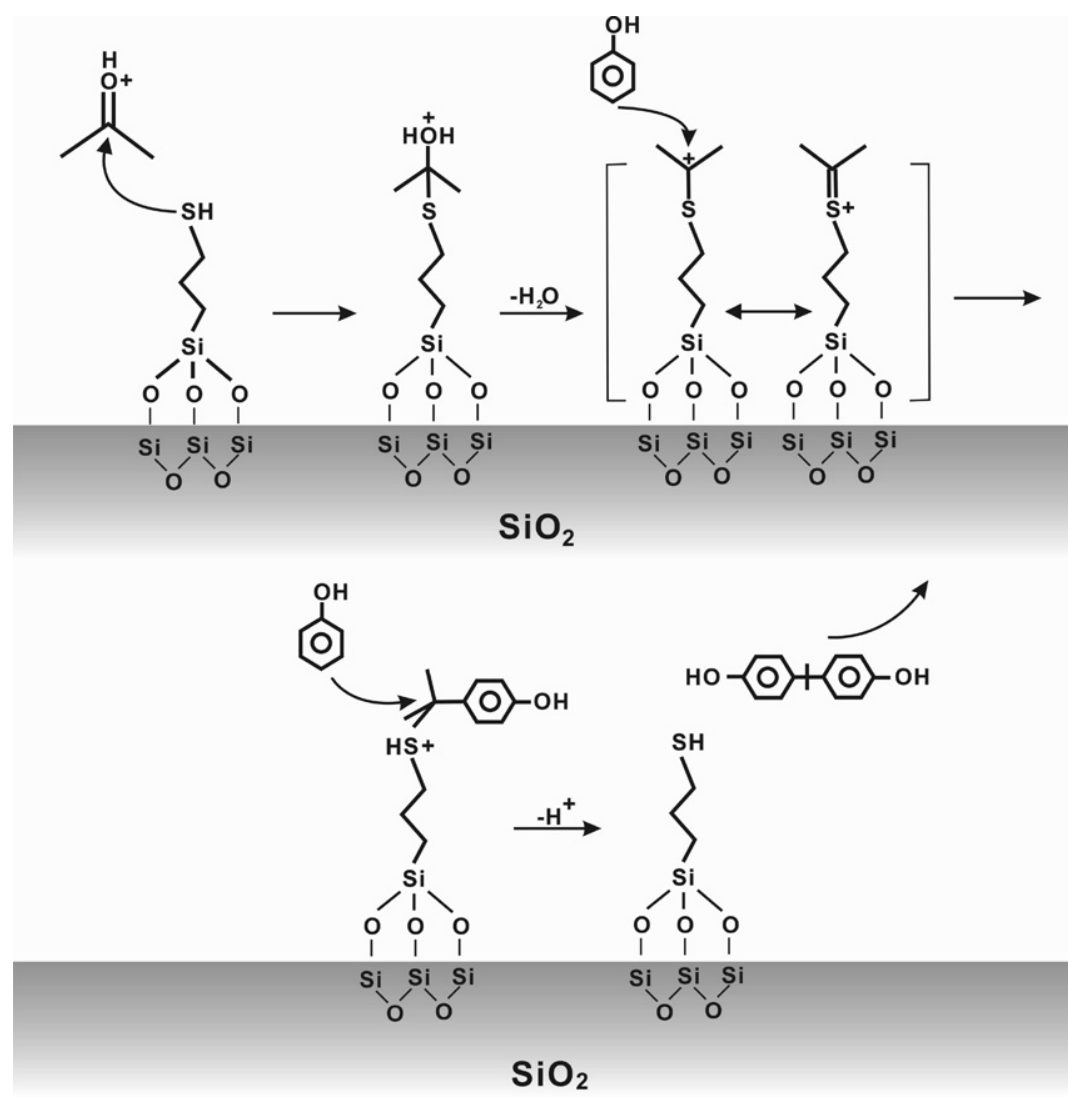

Scheme 2. Proposed mechanism for bisphenol-A formation over sulfonic acid and mercapto dual-functionalized mesoporous catalysts.

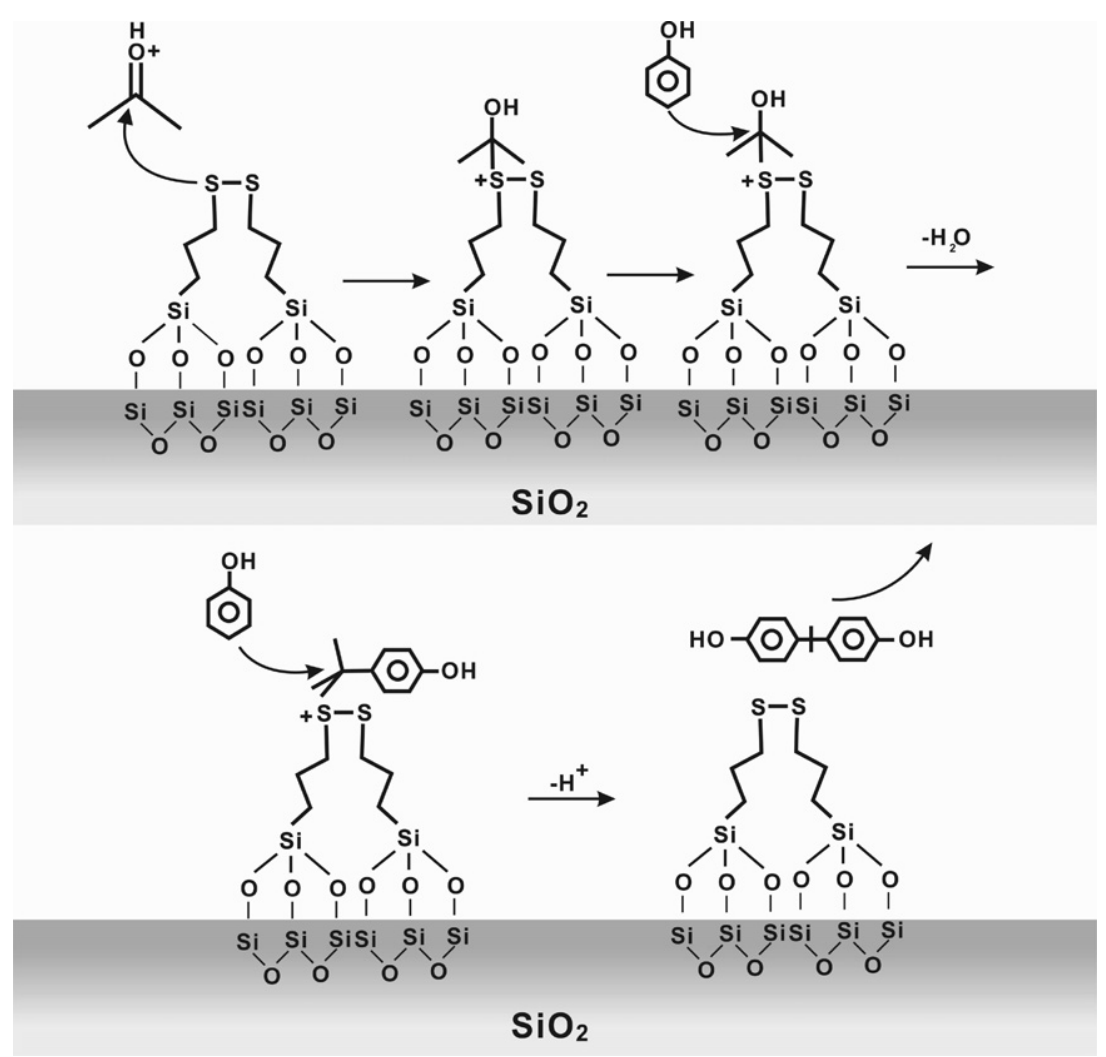

Scheme 3. Proposed mechanism for bisphenol-A formation over sulfonic acid and disulfide dual-functionalized mesoporous catalysts. 
reactants and the accessibility of the acidic and promoter sites in the pores. The irregularity of pore size in silica gel thus inhibits the catalytic reaction.

In order to test the stability of the catalyst in the liquid phase reaction, the $\mathrm{S} 15-\mathrm{Ar}_{-} \mathrm{SO}_{3} \mathrm{H}(10 \%)-\mathrm{SH}(15 \%)$ catalyst used in the condensation of phenol and acetone was regenerated by refluxing with ethanol for $24 \mathrm{~h}$. The regenerated catalyst was recovered by filtration and finally dried at $70{ }^{\circ} \mathrm{C}$. The catalytic results are also shown in Table 3 as entry 16. In comparison to that of fresh catalyst in entry 10 , the catalytic activity only slightly decreases and the selectivity to $p, p^{\prime}$-bisphenol-A remains almost unchanged. It demonstrates that most of the acid sites on the catalyst can be regenerate by simple washing and the catalyst can be used repeatedly under the present conditions.

\section{Conclusions}

The arenesulfonic acid and thiol (or disulfide) dual-functionalized mesoporous silica materials were successfully synthesized via one-pot co-condensation of silica and silane precursors in the presence of surfactant under acid condition. The sulfur K-edge XANES spectra showed that a large portion of the mercapto groups was oxidized to disulfide during the synthesis process, especially for the samples with low thiol contents. The hybrid mesoporous materials were more efficient than the merely arenesulfonic acid functionalized mesoporous silica or the commercial ion-exchange resin (Amberlyst-15), under the investigated condition, in catalyzing condensation reaction of phenol and acetone to form $p, p^{\prime}$-bisphenol-A. The sulfonic acid groups in the mesopores were found to serve as the catalytic active sites. However, the presence of mercapto or disulfide groups in proximity markedly increases the reaction rate and $p, p^{\prime}$-bisphenol-A selectivity by forming positive charged sulfide intermediates through nucleophilic attack on the protonated acetone and affecting the approach of phenol by steric hindrance. The promoting effect of disulfide was confirmed by preparing the sulfonic acid and disulfide dual-functionalized mesoporous catalyst and observed similar promoting effect as that over sulfonic acid and thiol dual-functionalized catalysts. However, the promoting efficiency of disulfide is slightly lower than that of mercapto groups. When the $\mathrm{SH} / \mathrm{SO}_{3} \mathrm{H}$ ratio was around 1.3-1.6, the optimal TONs of $p, p^{\prime}$-bisphenol-A which were higher than 100 could be obtained. On the other hand, ordered mesopores are important because they facilitate the diffusion of the reactants and the accessibility of the acid and promoter sites in the pores. The high catalytic activity and selectivity toward $p, p^{\prime}$-bisphenol-A formation of the dual-functionalized mesoporous catalysts can be regenerated by simple refluxing with ethanol.

\section{Acknowledgments}

The financial support from the National Science Council, Taiwan is gratefully acknowledged. Acknowledgments are also extended to Ms. C.-W. Lu and Mr. C.-Y. Tang of Instrumentation Center, NTU for the assistance in elemental analysis and EM experiments.

\section{References}

[1] R.B. Wagner, US Patent,3 172 916, to Hercules Powder Company 1965.

[2] B.W. McNutt, B.B. Gammill, L. Jackson, US Patent, 3394 089, to the Dow Chemical Company 1968.

[3] L.F. Albright, Oil Gas J. (1990) 71.

[4] K. Wilson, J.H. Clark, Pure Appl. Chem. 72 (2000) 1313.

[5] H. Ichihashi, H. Sato, Appl. Catal. A 221 (2001) 359.

[6] A. Commarieu, W. Hoelderich, J.A. Laffitte, M.P. Dupont, J. Mol. Catal. A 182 (2002) 37.

[7] G.A. Olah, S.I. Pradeep, G.K.S. Prakash, Synthesis (1986) 513.

[8] F.J. Waller, R.W. van Scoyoc, Chemtech 17 (1987) 438.

[9] A. Chakrabarti, M.M. Sharma, React. Polym. 20 (1993) 1.

[10] D. Margolese, J.A. Melero, S.C. Christiansen, B.F. Chmelka, G.D. Stucky, Chem. Mater. 12 (2000) 2448.

[11] S. Sadasivan, D. Khushalani, S. Mann, J. Mater. Chem. 13 (2003) 1023.

[12] S. Hamoudi, S. Kaliaguine, Micropor. Mesopor. Mater. 59 (2003) 195.

[13] J.G.C. Shen, R.G. Herman, K. Klier, J. Phys. Chem. B 106 (2002) 9975.

[14] Q. Yang, M.P. Kapoor, S. Inagaki, J. Am. Chem. Soc. 124 (2002) 9694.

[15] K. Wilson, A.F. Lee, D.J. Macquarrie, J.H. Clark, Appl. Catal. A 228 (2002) 127.

[16] I.K. Mbaraka, D.R. Radu, V.S.Y. Lin, B.H. Shanks, J. Catal. 219 (2003) 329.

[17] J.A. Melero, G.D. Stucky, R. van Grieken, G. Morales, J. Mater. Chem. 12 (2002) 1664.

[18] X.G. Wang, C.C. Chen, S.Y. Chen, Y. Mou, S. Cheng, S. Appl. Catal. A. 281 (2005) 47.

[19] V.M.V. Rhijn, D.E. De Vos, B.F. Sels, W.D. Bossaert, P.A. Jacobs, Chem. Commun. (1998) 317.

[20] I. Diaz, F. Mohino, J. Perez-Pariente, E. Sastre, Appl. Catal. A 205 (2001) 19

[21] I.K. Mbaraka, B.H. Shanks, J. Catal. 229 (2005) 365.

[22] A. Heidekum, M.A. Harmer, W.F. Hoelderich, J. Catal. 188 (1999) 230.

[23] I.J. Kijs, H.L.F. van Ochten, C.A. van Walree, J.W. Geus, L.W. Jenneskens, J. Mol. Catal. A 188 (2002) 209.

[24] D. Das, J.F. Lee, S. Cheng, Chem. Commun. (2001) 2178.

[25] D. Das, J.F. Lee, S. Cheng, J. Catal. 223 (2004) 152.

[26] R.K. Zeidan, V. Dufaud, M.E. Davis, J. Catal. 239 (2006) 299.

[27] Chen, C.C. Master thesis, National Taiwan University, 2004.

[28] V. Dufaud, M.E. Davis, J. Am. Chem. Soc. 125 (2003) 9403.

[29] J.G.C. Shen, T.H. Kalantar, R.G. Herman, J.E. Toberts, K. Klier, Chem. Mater. 13 (2001) 4479.

[30] D. Zhao, Q. Huo, J. Feng, B.F. Chmelka, G.D. Stucky, J. Am. Chem. Soc. 120 (1998) 6024.

[31] M. Llusar, G. Monros, C. Roux, J.L. Pozzo, C. Sanchez, J. Mater. Chem. 13 (2003) 2505.

[32] G. Sartori, F. Bigi, R. Maggi, R. Sartorio, D.J. Macquarrie, M. Lenarda, L. Storaro, S. Coluccia, G. Martra, J. Catal. 222 (2004) 410.

[33] W. van Rhijn, D. De Vos, W. Bossaert, J. Bullen, B. Wouters, P. Grobet, P. Jacobs, Stud. Surf. Sci. Catal. 117 (1998) 183.

[34] G.P. Huffman, N. Shah, F.E. Huggins, L.M. Stock, K. Chatterjee, J.J. Kilbane, M. Chou, D.H. Buchanan, Fuel 74 (1995) 549.

[35] G. Sarret, J. Connan, M. Kasrai, G.M. Bancroft, A. Charrie-Duhaut, S. Lemoine, P. Adam, P. Albrecht, L. Eybert-berard, Geochim. Cosmochim. Acta 182 (1999) 156.

[36] M. Kasrai, G.M. Bancroft, R.W. Brunner, R.G. Jonasson, J.R. Brown, K.H. Tan, X. Feng, Geochim. Cosmochim. Acta 58 (1994) 2865. 
[37] A. Prange, N. Kühlsen, B. Birzele, I. Arzberger, J. Hormes, S. Antes, P. Köhler, Eur. Food Res. Technol. 212 (2001) 570.

[38] J.P. Guif, Y. Dauphin, J. Doucet, M. Salome, J. Susini, Geochim. Cosmochim. Acta 67 (2003) 75.

[39] J. Hormes, U. Kuetgens, I. Ruppert, J. Phys. Colloq. 47 (1986) 569.
[40] G. Sarret, J. Connan, M. Kasrai, G.M. Bancroft, A. Charrié-Duhaut, S. Lemoine, P. Adam, P. Albrecht, L. Eybert-Bérard, Geochim. Cosmochim. Acta 63 (1999) 3767.

[41] K. Nowiǹska, W. Kaleta, Appl. Catal. A 203 (2000) 91. 